\title{
Prophylactic antibiotics in chronic umbilical artery catheterization in respiratory distress syndrome
}

\author{
HARRY BARD, GUY ALBERT, FRANÇOIS TEASDALE, BERNARD DORAY, and \\ BERNARD MARTINEAU \\ From the Department of Paediatrics, the Newborn Intensive Care Service, and the Department of Microbiology, Universite \\ de Montréal and Hôpital Sainte-Justine, Montreal, Canada
}

\begin{abstract}
Bard, H., Albert, G., Teasdale, F., Doray, B., and Martineau, B. (1973). Archives of Disease in Childhood, 48, 630. Prophylactic antibiotics in chronic umbilical artery catheterization in respiratory distress syndrome. The use of prophylactic antibiotics with indwelling umbilical artery catheters under continuous perfusion in 75 high risk newborns with respiratory distress syndrome (RDS) was evaluated. These infants were divided alternatively into 'treated' and 'nontreated' groups. The incidence of bacteraemia during chronic catheterization was $1.3 \%$, and the incidence of septic complications probably related to the catheterization was $2.6 \%$. There was a total of $11.7 \%$ colonization of catheter tips with pathogens, with no significant difference between the nontreated and the treated group. There was no difference in mortality or morbidity between the two groups. One nontreated infant showed a bacteraemia while an indwelling catheter was present, and a second was found to be septicaemic two days after removal. 2 infants, 1 from each group, developed a localized skin infection, probably related to catheterization. Antibiotic coverage during chronic umbilical artery catheterization in infants with RDS has dubious prophylactic value.
\end{abstract}

Umbilical artery catheterization is an accepted procedure for monitoring the arterial oxygenation and acid-base status of the sick newborn infant, particularly the preterm infant with respiratory distress syndrome (RDS). The advantages of indwelling umbilical artery catheters over capillary blood sampling are the reliability of umbilical artery $\mathrm{PO}_{2}$ measurements (Koch and Wendel, 1967; Glasgow, Flynn, and Swyer, 1972), the ease with which blood samples are withdrawn without disturbing a very sick infant with limited oxygen reserve, and the usefulness of this route for intravascular infusions of glucose and buffer solutions. There is still much concern as to the possible hazards and complications of umbilical artery catheterization. The following complications have been reported at necropsy: peritoneal perforation, accidental haemorrhage, embolization, extravascular catheter placement, thrombosis, arteritis, and perivascular haemorrhage; while clinically, blanching of the limb and alteration in pulse have been noted (Gupta, Roberton, and Wigglesworth,

Received 25 December 1972.
1968; Cochran, Davis, and Smith, 1968; Van Leeuwen and Patney, 1969; Larroche, 1970; Neal et al., 1972).

There have been few studies evaluating the risk of systemic and local infection associated with chronic umbilical artery catheterization. Symansky and Fox (1972) recently studied 112 infants with indwelling arterial catheters using continuous perfusion and systemic antibiotics. They had a mortality of $45 \%$ unrelated to the arterial catheters and an incidence of $6 \%$ colonization of the catheter tips with coagulase negative staphylococcus. Others (Vidyasagar, Downes, and Boggs, 1970), reporting on 124 infants with indwelling arterial catheters without continuous perfusion but covered with prophylactic antibiotics, observed an incidence of $10 \%$ of positive blood cultures via the catheters when taken at the moment of catheter withdrawal.

The present study was undertaken with the purpose of evaluating in infants with severe RDS (a) the dangers of systemic and local infection with the use of indwelling umbilical artery catheters using continuous fluid perfusion via the catheter, and (b) the role of systemic antibiotics as a prophylactic 
measure in preventing catheter tip colonization, bacteraemia, and localized infection.

\section{Materials and methods}

During the period 1 April 1971 to 30 March 1972, 75 newborn infants with RDS were studied in the neonatal intensive care unit of Ste-Justine's Hospital. The indications for umbilical arterial catheterization were clinical and radiological evidence of hyaline membrane disease and cyanosis with less than $50 \%$ ambient oxygen.

Technique of catheterization. Catheterization was performed under strict sterile conditions and temperature control. The umbilicus of the infant was washed first with tincture of iodine followed by $70 \%$ alcohol. The cord was then cut about 1 to $1.5 \mathrm{~cm}$ from the skin, and finally the cord stump was rewashed with tincture of iodine and alcohol. One of the umbilical arteries was identified and an iris forceps was carefully inserted into the lumen to reduce terminal spasm. Finally, a sterile polyvinyl end-hole umbilical catheter ${ }^{\star}\left(3 \frac{1}{2} \mathrm{~F}\right.$ or $\left.5 \mathrm{~F}\right)$ with radio-opaque marker was inserted into the umbilical artery and advanced for about 8 to $9 \mathrm{~cm}$, depending on the size of the infant. A lateral view $x$-ray was then taken specifically to check placement of the catheter which was adjusted in the abdominal aorta so that its tip was positioned between the level of L2-L3 (below the renal arteries and above the bifurcation of the iliac vessels). The catheter was then sutured in place. No topical antibiotics or dressings were applied to the junction of the cord and catheter. A sterile 3-way stopcock was attached to the catheter and a constant infusion of $10 \%$ dextrose and water with added buffer was maintained with a Holter pump.

For the purpose of the study, the catheterized infants were alternatively placed in one of two groups. (a) A 'treated' group of 37 infants received ampicillin $100 \mathrm{mg} /$ kg per $24 \mathrm{hr}$ intravenously in equally divided doses every $6 \mathrm{hr}$ and kanamycin $15 \mathrm{mg} / \mathrm{kg}$ per $24 \mathrm{hr}$ intramuscularly in equally divided doses every $12 \mathrm{hr}$, and (b) a 'nontreated' group of 38 received no antibiotics.

Culture technique. Upon insertion of the catheter, a sample $(1.5-3 \mathrm{ml})$ of blood was immediately obtained for culture and repeated daily. When conditions allowed for removal of the catheter, e.g. signs of clinical improvement together with $\mathrm{PO}_{2}$ maintained between 60 and $90 \mathrm{mmHg}$ in ambient oxygen of less than $50 \%$, the following procedures were performed. First, a peripheral blood culture was obtained from one of the upper extremities after sterilizing the skin with iodine and alcohol. A blood sample was then obtained via the umbilical catheter for culture. Finally, after thorough disinfection of the cord with iodine and alcohol, the catheter was removed under aseptic technique. As soon as the catheter was removed, the distal 1 to $2 \mathrm{~cm}$ was cut off allowing it to fall into a blood agar plate which was immediately transported to the laboratory where the

*Argyl Umbilical Artery Catheters, Sherwood Medical Industries Inc., St. Louis, Mo. 63103, U.S.A. catheter tip was then placed in cooked meat medium. In the event of a death, the catheter was immediately removed, the tip cultured, and a cardiac puncture performed for blood cultures. All the blood samples were inoculated into $50 \mathrm{~cm}^{3}$ thiol broth medium ${ }^{\star}$ and were processed by the bacteriology laboratory of the hospital using standard methods for identification of aerobic and anaerobic organisms.

In all instances: catheters were inserted within the first 24 hours of life. The effectiveness of the disinfecting technique was tested on umbilical cord swabs on 23 newborn infants before the insertion of the catheters only. All swabs except one were negative for both aerobic and anaerobic organisms. The technique was not tested when the catheters were removed. Cultures were also taken to test the sterility of the materials used in the study such as infusion fluids, catheters, and stopcocks. They were all negative.

Seven catheter tips could not be included in this evaluation because of faulty technique. 4 were in the treated group and 3 were in the nontreated group.

\section{Results}

Seventy-five infants were evaluated; their birthweights varying from 720 to $3500 \mathrm{~g}$ and gestational ages from 25 to 40 weeks. A total of 37 infants received prophylactic antibiotics. The distribution by birthweight and gestational age using the Colorado intrauterine growth charts is shown in Fig. 1 and 2.

Table I shows the number of colonizations of the

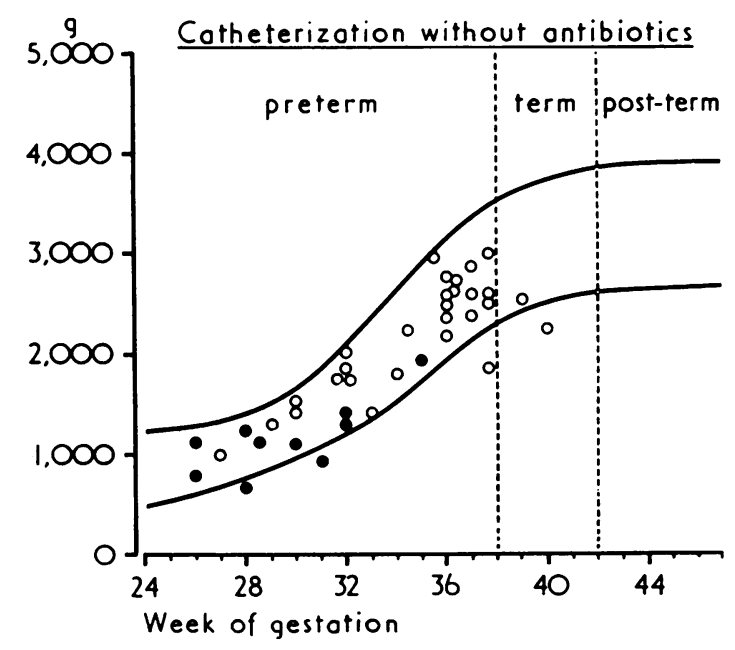

FIG. 1.-Distribution of nontreated newborn infants with $R D S$ on the Colorado intrauterine growth charts. Solid lines are the 10th and 90th centile limits. infants who died, $\bigcirc$ infants who survived.

*Bacto-Blood cultures Thiol Broth 0355-30. Difco Laboratories, Detroit, Michigan, U.S.A. 


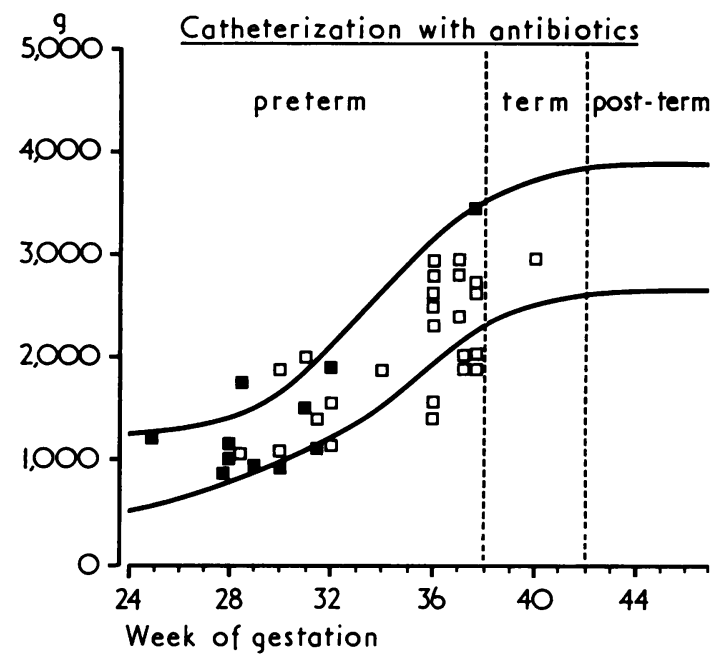

FIG. 2.-Distribution of the treated newborn infants with RDS on the Colorado intrauterine growth charts. Solid lines are the 10th and 90th centile limits. $\mathbf{\text { infants who }}$ died, $\square$ infants who survived.

TABLE I

Catheter tip contamination

\begin{tabular}{l|c|c}
\hline $\begin{array}{c}\text { No. of } \\
\text { catheter tips }\end{array}$ & $\begin{array}{c}\text { With antibiotics } \\
(\text { no. = 33) }\end{array}$ & $\begin{array}{c}\text { Without antibiotics } \\
\text { (no. = 35) }\end{array}$ \\
\hline $\begin{array}{l}\text { No growth } \\
\text { Growth }\end{array}$ & 25 & 16 \\
& 8 & 19 \\
\hline
\end{tabular}

${ }^{\star} \chi^{2}$ with Yates' correction $=7 \cdot 72, P<0.01$.

catheter tips. Those receiving antibiotics had significantly fewer contaminated catheter tips $(\mathrm{P}<0 \cdot 01)$.

The bacteria were divided into what are considered pathogens (Staphylococcus aureus, $\beta$ haemolytic streptococcus, Group D streptococcus, Enterobacteriaceae, and Pseudomonas aeruginosa) and nonpathogens (Staphylococcus epidermidis (Staph. albus), Micrococcus sp., $a$-haemolytic streptococcus, and diphtheroids). The incidence of pathogens and nonpathogens is illustrated in Table II. The difference was not significant statistically $(P<0 \cdot 1)$.

Table III shows the type of bacteria isolated from catheter tips in both groups studied. The most prominent type was Staph. epidermidis (Staph. albus).

The duration of catheterization was 5 to 7 days in $34 \%$ of the cases, 2 to 4 days in $65 \%$ of the cases, and less than 24 hours in $10 \cdot 6 \%$ studied. (There
TABLE II

Catheter tip contamination with pathogens ${ }^{\star}$

\begin{tabular}{l|c|c}
\hline $\begin{array}{c}\text { No. of } \\
\text { catheter tips }\end{array}$ & $\begin{array}{c}\text { With antibiotics } \\
\text { (no. = 33) }\end{array}$ & $\begin{array}{c}\text { Without antibiotics } \\
\text { (no. = 35) }\end{array}$ \\
\hline $\begin{array}{l}\text { No growth } \\
\text { Growtht }\end{array}$ & 31 & 29 \\
\hline
\end{tabular}

* There was a single mortality which was in the nontreated group. $t \chi^{2}$ with Yates' correction $=2 \cdot 186, P>0 \cdot 1$.

TABLE III

Catheter tip colonization

I. With antibiotics

Staph. epidermidis (Staph. albus)

Staph. aureus

Group D streptococcus

7
2
1
12
1
2
2
1
1
3
1

was no correlation between the length of catheterization and the incidence of colonization.)

The results of the blood cultures via the catheter just before withdrawal are shown in Table IV. There was a statistically significant decrease in positive cultures in those withdrawn from infants receiving prophylactic antibiotics $(P<0.01)$. Again, there was a predominance of Staph. epidermidis (Staph. albus) as shown in Table V. The incidence of pathogens was $4 \%$ of all cultures, and these were isolated exclusively in those infants not receiving antibiotics.

Table VI illustrates 3 infants who had positive peripheral blood cultures. In one infant Corynebacterium $\mathrm{sp}$. was found in a single peripheral blood culture and was considered a contaminant.

TABLE IV

Blood culture via catheter before catheter withdrawal

\begin{tabular}{l|c|c}
\hline & With antibiotics & Without antibiotics \\
\hline $\begin{array}{l}\text { No growth } \\
\begin{array}{l}\text { Growth* } \\
\text { Total number } \\
\text { of patients }\end{array}\end{array}$ & 89 & 19 \\
& 37 & 38 \\
\hline
\end{tabular}

$\star \chi^{2}$ with Yates' correction $=7 \cdot 84, P<0 \cdot 01$. 
TABLE V

\section{Catheter blood culture at removal}

I. With antibiotics

Staph. epidermidis (Staph. albus)

$\alpha$-haemolytic streptococcus

II. Without antibiotics

Staph. epidermidis (Staph. albus) 14

$\alpha$-haemolytic streptococcus 2

Enterobacter cloacae

Ps. aeruginosa

The infant was in the nontreated group and had a favourable outcome. The second case was a nontreated infant weighing $920 \mathrm{~g}$ whose gestational age was 31 weeks. When this infant died at 3 days of age, a blood culture withdrawn via a cardiac puncture showed Ps. aeruginosa, and this was also isolated in the blood withdrawn via the catheter before death, though the tip only grew Staph. epidermidis (Staph. albus), Micrococcus sp., and diphtheroids. This infant had negative peripheral and catheter blood cultures approximately 24 hours before death. Finally, in one other nontreated infant Staph. aureus was isolated 2 days after catheter removal in a peripheral blood culture performed as a sepsis investigation because of clinical indications. In this infant Staph. aureus was also isolated from the cord before catheter insertion and on the catheter tip after withdrawal. The cultures from the peripheral blood and the blood drawn via the catheter during the 2 days of catheterization were negative. The strains of staphylococcus isolated from the 3 different sites all belonged to the phage type group 3 and showed a similar phage pattern. If we discard the case with the contaminant, then the incidence of sepsis possibly related to arterial catheterization was $2 \cdot 6 \%$.

There were two infants in whom a localized umbilical infection could have been related to the catheters. In both cases Staph. aureus was isolated from the cord. One case was an infant in the treated group, $1000 \mathrm{~g}$ birthweight and 28 weeks' gestation, who had a purulent exudation from the umbilicus which grew Staph. aureus. The catheter was removed, blood cultures were negative, and the infant died because of respiratory insufficiency at 4 days of age. The second infant in the nontreated group, weighing $920 \mathrm{~g}$ at 28 weeks' gestation, showed a purulent umbilical exudation 8 days after catheter removal which also grew Staph. aureus. A blood culture was negative. This infant then received appropriate systemic antibiotics and had a favourable outcome.

The sex distribution in relation to the mortality and the cultures which grew pathogens in both groups are shown in Table VII. The sex of the

TABLE VI

Positive peripheral blood cultures ${ }^{\star}$

\begin{tabular}{|c|c|c|c|c|c|c|}
\hline $\begin{array}{c}\text { Case no. } \\
\text { (nontreated) }\end{array}$ & $\begin{array}{l}\text { Birthweight } \\
(\mathrm{g})\end{array}$ & $\begin{array}{l}\text { Gestation } \\
\text { (wk) }\end{array}$ & Peripheral blood & Cord blood & Catheter tip & Outcome \\
\hline 71 & 920 & 28 & $\begin{array}{l}\text { Corynebacterium } \\
\text { acnes }\end{array}$ & Negative & Negative & Favourable \\
\hline 28 & 920 & 31 & $\begin{array}{l}\text { Ps. aeruginosa (cardiac } \\
\text { puncture) }\end{array}$ & Ps. aeruginosa & $\begin{array}{l}\text { Staph. epidermidis } \\
\text { (Staph. albus), } \\
\text { Micrococcus sp., } \\
\text { diphtheroids }\end{array}$ & Died \\
\hline 19 & 1440 & 30 & $\begin{array}{l}\text { Negative; Staph. } \\
\text { aureus } 2 \text { days after } \\
\text { catheter removal }\end{array}$ & Negative & $\begin{array}{l}\text { Staph. aureus } \\
\text { (also isolated } \\
\text { from cord } \\
\text { swab) }\end{array}$ & Favourable \\
\hline
\end{tabular}

$\star 3$ out of 75

TABLE VII

Sex distribution of pathogenic growth and mortality

\begin{tabular}{|c|c|c|c|c|}
\hline & \multicolumn{2}{|c|}{ With antibiotics } & \multicolumn{2}{|c|}{ Without antibiotics } \\
\hline & Male (20) & Female (17) & Male (26) & Female (12) \\
\hline $\begin{array}{l}\text { Catheter blood culture } \\
\text { Pathogens } \\
\text { Catheter tip culture } \\
\text { Pathogens } \\
\text { Mortality }\end{array}$ & $\begin{array}{l}0 \\
1 \\
6\end{array}$ & $\begin{array}{l}0 \\
1 \\
5\end{array}$ & $\begin{array}{l}1 \\
5 \\
5\end{array}$ & $\begin{array}{l}1 \\
1 \\
5\end{array}$ \\
\hline
\end{tabular}


newborn infants did not affect the mortality rates nor were there statistically significant differences between males and females in any of the parameters studied.

The neonatal mortality distribution of the nontreated and treated groups are shown in Fig. 1 and 2 , respectively. The incidence was $26.3 \%$ in the nontreated compared to $29.7 \%$ in the treated group. There was no statistically significant difference. The mortality was confined, as expected in severe RDS, to the extreme low birthweight populations in both groups. Necropsy studies revealed that all deaths were related to hyaline membrane disease.

\section{Discussion}

The study was confined to infants with RDS, since the disease process is one without an infectious aetiology. Furthermore, the infants requiring more than $50 \%$ ambient oxygen were catheterized since these infants needed careful oxygen monitoring and thus warranted chronic umbilical artery catheterization.

There was virtually no evidence of bacterial contamination upon insertion of the catheters in this study and this is supported by Fairchild $e t$ al. (1958) who showed that $85 \%$ of infants whose umbilical cords were cultured on the first day of life had no bacterial growth. Subsequently there was a rapid colonization, such that by the second day of life bacterial growth was shown in more than $80 \%$ of the umbilical cord swabs. Andersen and Holm (1963) also showed in their study that positive umbilical stump cultures appeared only after 48 hours of life. Balagtas et al. (1971), whose sterilization technique of the umbilical region before catheter removal was similar to the methods herein employed, reported that upon removing their catheters there was an $82 \%$ incidence of bacterial colonization of the umbilicus, $29 \%$ of which were pathogens, and it did not make any difference if the infants were receiving systemic antibiotics. For the interpretation of the rate of catheter tip colonization in our study, it would have been of great value to have had data on cultures of umbilical cord tissue obtained on catheter withdrawal.

In studies by others using blood withdrawn through indwelling umbilical catheters, the incidence of positive cultures was reported as $10 \%$ in infants receiving systemic antibiotics and $43 \%$ in infants without antibiotherapy (Lipsitz, and Cornet, 1960; Krauss, Albert, and Kannan, 1970; Vidyasagar et al., 1970). Our results showed $21 \%$ incidence of positive cultures in the treated infants vs $50 \%$ in the nontreated infants. There was only one case of actual bacteraemia in our study during catheterization, which strongly suggests that positive cultures obtained via the catheter do not reflect the presence of bacteria in the blood stream. The significance of finding less bacterial growth in the blood withdrawn through catheters from infants on antibiotherapy must be interpreted with caution, since it can be explained by the presence of antibiotics in the blood withdrawn through the catheter preventing growth in the culture media.

Bacterial contamination of catheters as a complication of umbilical artery catheterization has been reported in several published studies. Krauss et al. (1970) showed that 6 out of 11 umbilical artery catheter tips removed from infants receiving antibiotics grew bacteria. Balagtas et al. (1971), evaluating umbilical vein catheters in a similar group of newborn infants, showed $52 \%$ were contamined. Symansky and Fox (1972), on the other hand, in 112 treated infants, showed an incidence of bacterial growth in $6 \%$ of the umbilical artery catheter tips. In our study the incidence of positive catheter tips in the treated infant lies between the two ends of the spectrum, being $24 \%$, of which $6 \%$ were pathogens.

The overall incidence of septicaemia related to umbilical artery catheterization was $2 / 75$ or $2.6 \%$ (both cases were in the nontreated group). The actual incidence of bacteraemia while using an indwelling catheter was $1 / 75$ or $1 \cdot 3 \%$. The one case was a $920 \mathrm{~g}$ infant and Ps. aeruginosa was isolated from blood both from cardiac puncture and via the catheter, though it was not colonized on the tip. This infant had been intubated and artificially ventilated for more than 24 hours before death. Infections caused by $P$ s. aeruginosa are almost always a complication of other diseases, particularly in prematures with RDS who have been mechanically ventilated (Barson, 1971). Thus, the pseudomonas septicaemia may not have been related to the catheterization.

There were more males than females whose RDS required an umbilical artery catheterization (61\%). But there were no sex differences in mortality or bacterial complications.

There was no difference in neonatal mortality between the treated and nontreated groups, and the overall mortality was $28.0 \%$. This incidence was considered favourable when evaluating infants with RDS in which the total mortality figures varied from 20 to $30 \%$ (Stahlman et al., 1967; Usher, 1963). Also, in this study we selected, because of our clinical criteria, those infants whose prognosis was the worst. Except for a severely asphyxiated infant of a diabetic mother, those who died were of very 
low birthweight and of low gestational age. The cause of death in all infants, with the possible exception of the infant with pseudomonas septicaemia, was due to pulmonary insufficiency.

The presence of indwelling catheters permits easy access to arterial blood, thus allowing the initiation of therapy such as oxygen regulation or artificial ventilation before an irreversible situation becomes apparent. With the catheter tip localized between L2-L3 under continuous perfusion, we did not experience any complications.

In spite of the high rate of colonization, the risk of bacteraemia associated with umbilical artery catheterization using the technique described was minimal. The one true case of bacteraemia during catheterization would not have been appropriately covered in any case with the antibiotics employed. Though suggestive, there was no statistically significant decrease in the pathogens colonized on the catheter tips in the treated infants. Also, there was no difference in mortality between the treated and the nontreated groups. Furthermore, the large spectrum of bacteria would make the use of appropriate prophylactic antibiotherapy illogical as it could result in the selection of resistant types which would then be difficult to treat. Though there was still a high incidence of pathogens isolated from the catheter tips, none among these showed a bacteraemia, and all survivors have been followed without any evidence of sepsis. This procedure carries a certain risk of infection and it should be reserved for specific clinical indications. The catheters should only be inserted under strict sterile conditions by experienced physicians in intensive care units staffed by specially trained personnel. Once the catheter is in place, these infants require judicious surveillance and daily blood cultures. In the presence of a positive catheter blood culture, a peripheral blood culture should be done to rule out a bacteraemia. If pathogens are shown in any of the blood cultures, appropriate antibiotherapy is warranted. The need for maintaining an indwelling catheter should be continuously re-evaluated and it should be removed as soon as possible.
The authors are grateful for the assistance of the nursing staff of the Intensive Care Nursery, and of the microbiological laboratory technicians of Hôpital Sainte-Justine.

\section{REFERENCES}

Andersen, H. J., and Holm, S. E. (1963). A bacteriological comparison between two methods of exchange transfusion. Acta Paediatrica, 52, 143.

Balagtas, R. C., Bell, C. E., Edwards, L. D., and Levin, S. (1971). Risk of local and systemic infections associated with umbilical vein catheterization: a prospective study in 86 newborn patients. Pediatrics, 48, 359.

Barson, A. J. (1971). Fatal Pseudomonas aeruginosa bronchopneumonia in a children's hospital. Archives of Disease in Childhood, 46, 55.

Cochran, W. D., Davis, H. T., and Smith, C. A. (1968). Advantages and complications of umbilical artery catheterization in the newborn. Pediatrics, 42, 769.

Fairchild, J. P., Graber, C. D., Vogel, E. H., and Ingersoll, R. L. (1958). Flora of the umbilical stump. Fournal of Pediatrics, $53,538$.

Glasgow, J. F. T., Flynn, D. M., and Swyer, P. R. (1972). A comparison of descending aortic and arterialized capillary blood in the sick newborn. Canadian Medical Association fournal, 106, 660 .

Gupta, J. M., Roberton, N. R. C., and Wigglesworth, J. S. (1968). Umbilical artery catheterization in the newborn. Archives of Disease in Childhood, 43, 382.

Koch, G., and Wendel, H. (1967). Comparison of ph, carbon dioxide tension, standard bicarbonate and oxygen tension in capillary blood and in arterial blood during the neonatal period. Acta Paediatrica Scandinavica, 56, 10.

Krauss, A. N., Albert, R. F., and Kannan, M. M. (1970). Contamination of umbilical catheters in the newborn infant. Fournal of Pediatrics, 77, 965.

Larroche, J. C. (1970). Umbilical catheterization: its complications. Biology of the Neonate, 16, 101.

Lipsitz, P. J., and Cornet, J. M. (1960). Blood cultures from the umbilical vein in the newborn infant. Pediatrics, 26, 657.

Neal, W. A., Reynolds, J. W., Jarvis, C. W., and Williams, H. J. (1972). Umbilical artery catheterization: demonstration of arterial thrombosis by aortography. Pediatrics, 50, 6.

Stahlman, M. T., Battersby, E. J., Shepard, F. M., and Blankenship, W. J. (1967). Prognosis in hyaline-membrane disease. New England Fournal of Medicine, 276, 303.

Symansky, M. R., and Fox, H. A. (1972). Umbilical vessel catheterization: indications, management, and evaluation of the technique. Fournal of Pediatrics, 80, 820.

Usher, R. (1963). Reduction of mortality from respiratory distress syndrome of prematurity with early administration of intravenous glucose and sodium bicarbonate. Pediatrics, 32, 966.

Van Leeuwen, G., and Patney, M. (1969). Complications of umbilical vessel catheterization: peritoneal perforation. Pediatrics, 44, 1028.

Vidyasagar, D., Downes, J. J., and Boggs, T. R. (1970). Respiratory distress syndrome of newborn infants. II. Technic of catheterization of umbilical artery and clinical results of treatment of 124 patients. Clinical Pediatrics, 9, 332.

Correspondence to Dr. H. Bard, Department of Paediatrics, Hôpital Sainte-Justine, 3175 Chemin SainteCatherine, Montreal 250, Canada. 